\section{Menuchim, Hiob, Ustim}

H. Vogt

Mendel Singer war der allergewöhnlichste Dorfschullehrer in ganz Galizien. Seine Hütte besass einen einzigen Raum, Küche, Schlafzimmer und Schulstube zugleich. "Sein Leben rann stetig dahin, wie ein kleiner armer Bach zwischen kärglichen Ufern.» Diesen stetigen Lauf der Dinge unterbrach die Geburt Menuchims. "Sein grosser Schädel hing schwer wie ein Kürbis an seinem dünnen Hals. Seine breite Stirn fächelte und furchte sich kreuz und quer wie ein zerknittertes Pergament. Lächerliche Laute stammelte sein Mund.»

Eines Tages konnte Menuchim sprechen - ein einziges Wort: Mama. «Dieses eine Wort der Missgeburt war erhaben wie eine Offenbarung, mächtig wie ein Donner, gnädig wie der Himmel, fruchtbar wie ein Acker.» Aber mehr kam nicht aus seiner Kehle.

Seine Mutter suchte den Rat eines Fachmannes und erhielt eine verheissungsvolle, wenn auch rätselhafte Prognose: «Der Schmerz wird ihn weise machen, die Hässlichkeit gütig, die Bitternis milde und die Krankheit stark.»

Die Jahre vergehen. Zusammen mit seinen Geschwistern wächst Menuchim auf. Seine älteren Brüder werden zum Militärdienst eingezogen - eine Katastrophe für eine jüdische Familie, die sich mit Selbstverständlichkeit an die Speisegebote hält. Der eine kann sich nach Amerika absetzen, der zweite wird Kosak. Die Kosaken sind auch hinter der Schwester her, sie droht zu einer Soldatenbraut zu werden - oder noch schlimmer. Mendel Singer hält das nicht mehr aus. Eingeladen von seinem Sohn, der die Reise bezahlt, wandert er mit Frau und Tochter nach Amerika aus. Er kostet die Speise der Heimatlosigkeit und wird gepeinigt von Gewissensqualen, Menuchim im Stich gelassen zu haben. Dann kommt der Krieg. Der Sohn wird eingezogen und fällt. Die böse Nachricht fordert das Leben der Mutter. Die Tochter verliert den Verstand.

"Ich esse und trinke, bete und atme. Aber mein Blut stockt, meine Hände sind welk, mein Herz ist leer. Ich bin nicht Mendel Singer mehr, ich bin der Rest von Mendel Singer. Amerika hat uns getötet.»
Leer und verloren geht Mendel Singer seinen Weg weiter - den Weg Hiobs. Joseph Roth, der diese Geschichte [1] aufgeschrieben hat, ist ihm nahe verwandt: Leer und verloren treibt er sich in Paris herum, weil in Deutschland seines Bleibens nicht mehr ist. Notdürftig betäubt er seine Verzweiflung mit Alkohol und stirbt mit 45 Jahren. Es ist höchste Zeit. Im Jahr darauf übernehmen die Nazis in Paris die Kontrolle.

Mendel Singer hat seinen Menuchim längst aufgegeben, als in New York ein Orchester auftritt mit einem Kapellmeister, der auch als Komponist berühmt geworden ist. Mendel begegnet seinem Sohn Menuchim, der auf Umwegen Aufnahme gefunden hat bei der Familie eines Arztes in St. Petersburg, genesen ist und eine einzigartige Beziehung zum Reich der Töne entwickelt hat. Die Botschaft des Buches Hiob lautet: Auch Missratenes, Fehlerhaftes und Zerbrochenes kann eines Tages im Schimmer des Vollendeten erglänzen.

Ustim lebt als erstes Kind von hochbegabten Eltern im heutigen ukrainischen Lemberg, der früheren Hauptstadt des österreichischen Galiziens. Ein autistisches Kind. Ständig ist er in Bewegung - in bizarrer Bewegung, wie ein Kreisel sich im Raum drehend oder behende eine Leiter erkletternd, kaum erträglich für die Zuschauer, welche in der nächsten Sekunde den Absturz erwarten. Eine verstümmelte Sprache kommt aus seiner Kehle; Laute, die nur seiner Mutter oder den nächsten Angehörigen verständlich sind. Er läuft davon, wenn er ohne Aufsicht ist, gerät in den Gewahrsam der Polizei, von wo ihn die Eltern nach Hause holen. Seinem Alter entsprechend gehörte Ustim in die Schule - aber da ist keine Schule für autistische Kinder. Aus der Sonderschule wurde er nach kurzer Zeit weggewiesen. Er störte. Seine Familie kann keinerlei Hilfe erwarten. Wird einstmals in ferner Zukunft auch im Leben des Ustim der Schimmer des Vollendeten aufscheinen? Für diese Annahme gibt es keinerlei vernünftige Argumente. Trotzdem:

Mit Hilfe der Caritas Deutschland möchten die Eltern mit anderen Direktbetroffenen in einem ersten Schritt eine Selbsthilfegruppe gründen. Später möglicherweise eine Tagesschule und einen Behindertentransportdienst. Die Ärztepartnerschaft Bern-Lemberg (Bär und Leu) hat die Patenschaft übernommen.

Einige möchten wisse, wie es dem Findelkind Vera Rapoport geht [2]: sie hat Aufnahme gefunden in der Familie eines Priesters, der schon drei eigene Kinder hat. Sie hat nochmals Glück gehabt. Das Waisenhaus ist ihr erspart geblieben.

\footnotetext{
Literatur

1 Roth J. Hiob. Köln: Kiepenheuer \& Witsch; 2000

2 Vogt H. Der wimmernde Wicht und der Rabbi von Porto. Schweiz Ärztezeitung 2000;81(47):2683-4.
}

Korrespondenz:

Heiner Vogt

"Bär und Leu»

Kirchweg

CH-3704 Krattigen

E-mail: heiner@vogt.org 